\title{
$\$$ Research Square

\section{Chemotherapeutic drugs in Lebanese surface waters: estimation of population exposure and identification of high-risk drugs}

\section{Yolande Saab ( $\nabla$ ysaab@lau.edu.lb )}

Lebanese American University School of Pharmacy

\section{Zahi Nakad}

LAU

\section{Rita Rahme}

LAU

\section{Research}

Keywords: Anticancer drugs, micropollutants, risk assessment, predicted environmental concentrations, WWTP, surface waters, Lebanon.

Posted Date: February 1st, 2021

DOI: https://doi.org/10.21203/rs.3.rs-98879/v2

License: (a) (i) This work is licensed under a Creative Commons Attribution 4.0 International License. Read Full License 


\section{Abstract}

Environmental risk assessment of anti-cancer drugs and their transformation products is a major concern worldwide due to two main factors: the consumption of chemotherapeutic agents is increasing throughout the years and conventional water treatment processes seem to be ineffective. The aim of the study is to investigate the consumption of anticancer drugs and assess their potential health hazard as contaminants of the Lebanese surface waters. Data on yearly consumption of 259 anti-neoplastic drugs over the years 2013 to 2018 were collected and the following parameters were calculated: yearly consumption of single active ingredients, yearly consumption of drug equivalents (for drugs belonging to the same pharmacologic class/ having the same active ingredient) and Predicted Environmental Concentrations (PECs). The classification of compounds into risk categories was based on exposure using PECs. The top five most commonly consumed drugs are Mycophenolate mofetil, Hydroxycarbamide, Capecitibine, Mycophenolic acid and Azathioprine. Based on the calculated PEC values of single active ingredients as well as their equivalents, six high risk priority compounds were identified: Mycophenolate mofetil, Hydroxycarbamide, Capecitibine, Mycophenolic acid and Azathioprine and 5-Fluorouracil. The impact of these micropollutants on animals as well as humans was analyzed. This research paper stresses the importance of further analysis of chemotherapy micropollutants with major focus on high risk drugs. Additionally, regulations should be set in place to ensure proper management of waste water and the development of efficient waste water treatment plants.

\section{Introduction}

Cancer is the second leading cause of death in the world. Every sixth death in the world is due to cancer [1]. In Lebanon, the number of new cancer cases diagnosed in 2018 is 17294 cases (288 cases per 100,000 population) with breast, bladder, lung, prostate, and colorectal cancers being the most common [2]. The number of death from cancer has doubled between the years 2000 (3776 deaths) and 2017 (6639 deaths) with a relative increase in less than $1.5 \mathrm{M}$ in Lebanese population [2]. As the world population is growing and aging, the global number of cancer death is expected to increase further. Chemotherapy is often used as a major treatment for almost all types of cancer. Cytotoxic drugs are a group of compounds used in chemotherapy to prevent or disrupt cell division. There are over 50 cytotoxic drugs used routinely in chemotherapy.

Chemotherapeutic agents can be classified into different categories based on their chemical structures and the way they act on cancer cells. Most commonly used agents are alkylating agents, which act directly on DNA, causing cross-linking of DNA strands, abnormal base pairing, or DNA strand breaks, thus preventing the cell from dividing. Another class of commonly used chemotherapeutic drugs are antimetabolites, which replace natural substances as building blocks in DNA molecules, thereby altering the function of enzymes required for cell metabolism and protein synthesis. Plant alkaloids are antitumor agents derived from plants. These drugs act specifically by blocking the ability of a cancer cell to divide and become two cells. Another major class are antitumor antibiotic. They act by binding with DNA and preventing RNA synthesis, a key step in the creation of proteins, which are necessary for cell survival. Many of these drugs are mutagenic, carcinogenic, teratogenic and/or toxic to reproductive systems and are classified as highly hazardous compounds [3].

Anticancer drugs present as a major water contaminant worldwide; Lebanon's case is not less worrisome. Environmental risk assessment of anti-cancer drugs and their transformation products is a major concern worldwide; studies have been conducted to analyze chemotherapy drugs consumption trends, availability in 
surface water and population exposure. This is due to two main factors: the consumption of chemotherapeutic agents is increasing throughout the years and conventional water treatment processes seem to be ineffective. Many research studies reported that waste water treatment plants (WWTPs), even those that meet regulatory requirements for waste water treatment, are only moderately effective in removing the aforementioned pharmaceuticals[4-7]. The pharmacologic properties and mutagenic properties of chemotherapy drugs potentially make anticancer drugs the most dangerous contaminant of our water system and pose a risk to the aquatic life and human beings. Available ecotoxicological data for anti-cancer drugs and their metabolites are incomplete. So far, the situation in Lebanon was not evaluated by any environmental risk assessment studies. Our work is the first to present an overview of the consumption trends in Lebanon, to forecast the presence of the associated contaminants in surface waters, and to conclude with an assessment of the correlated risks. The assessment will take into consideration the pharmacokinetic properties (metabolism and excretion) of each of the anticancer drugs analyzed.

The aim of the study is to investigate the consumption of anticancer drugs and assess their potential health hazard toxic effects as contaminants in the environment.

\section{Materials And Methods}

The work is divided into five steps:

- Study the consumption of chemotherapy drugs in Lebanon over the years 2013 to 2018.

- Compute the concentration of these drugs in surface water.

- Investigate the exposure of the Lebanese population to anticancer drugs.

- Assess the long term risks associated with this exposure and the potential effect on Lebanon as well as countries on the Mediterranean Sea.

\subsection{Anticancer drugs consumption}

The brand names of cancer drugs available on the Lebanese market and registered at the Ministry of Public Health (MOPH) were identified, and the yearly consumption of each drug consumed between 2013 and 2018 was studied. Data comprised all the dosage forms available on the Lebanese market including tablets, capsules and injectable drugs. As per the MOPH, anticancer drugs are classified as: endocrine therapy, immunosuppressive agents and antineoplastic agents.

\subsection{Data collection and concentration in surface water}

Consumption data was identified for 259 anti-neoplastic drugs over six years. The total amount of active ingredients consumed over the years was calculated based on the following:

- For every brand drug, consumption per year (in $\mathrm{mg}$ ) was calculated using the number of boxes (preparations) consumed $x$ the number of units/box and the amount of active ingredients in each unit (in $\mathrm{mg})$.

- Drugs with the same active ingredient were grouped together and their consumption was summed up. 
- When applicable, different active ingredients belonging to the same pharmacologic or chemical class were grouped together. Total consumption in every drug class was calculated using conversion factors, as provided in Table 1.

- Cumulative concentration was calculated by summing the total consumption per year for the years 2013 to 2018.

\subsection{Exposure based classification}

Pharmaceuticals that are used in higher amounts have a potential to reach the aquatic environment in greater quantities and therefore present a higher risk to human and aquatic life. Therefore, risk classification is done according to quantity consumed. The classification of compounds based on exposure is done using Predicted Environmental Concentrations (PECs), according to Scheme 1. Thresholds for risk classification adopted in the analysis are $100 \mathrm{ng} \mathrm{L}^{-1}$ (guidance by the Food and Drug Administration- FDA [14] and $10 \mathrm{ng} \mathrm{L}^{-1}$ (guidance by European Medicine Agency- EMEA [15] Two PEC values were determined:

- PEC ${ }_{a}$ assumes no metabolism of the active ingredient happens in the body, $100 \%$ of the active ingredient is excreted unchanged.

(1) $\mathrm{PEC}_{\mathrm{a}}=\frac{\text { consumption }}{\text { WWinhab } x \text { inhab } x D F}$

Where Consumption is the amount of active ingredient consumed per year $\left(n g\right.$ year $\left.{ }^{-1}\right)$ WWinhab is the water consumption per person per year, Inhab is the number of inhabitants of Lebanon and DF is the dilution factor from WWTPs effluents to surface water.

- $\mathrm{PEC}_{\mathrm{b}}$ is calculated when metabolism data is available for the drug. The fraction of active ingredient excreted unchanged $\left(\mathrm{F}_{\text {exc }}\right)$ is added to the equation.

(2) $\mathrm{PEC}_{b}=\frac{\text { consumption }}{\text { WWinhab } x \text { inhab } x \text { DF }} \times$ Fexc

- $\mathrm{PEC}_{\mathrm{c}}$ is the predicted concentration in surface water that remains after treatment. Therefore, $\mathrm{PEC}_{\mathrm{c}}$ is obtained by taking into consideration the fraction of pharmaceuticals removed by WWTPS ( $F_{\text {WWTP }}$ ). However, due to the absence of efficient treatment plants or the absence of data in Lebanon, the FWWTP was assumed to be equal to zero. $\mathrm{PEC}_{\mathrm{c}}$ and $\mathrm{PEC}_{\mathrm{b}}$ values are therefore equal.

(3) $\mathrm{PEC}_{\mathrm{c}}=\frac{\text { consumption }}{\text { WWinhab } x \text { inhab } \times \text { DF }} \times$ Fexc $x\left(1-F_{\text {WWTP }}\right)$

The following assumptions were made when using the formula: 
- According to the EMEA guidelines, the amount of waste water per inhabitant per day to be equal to $200 \mathrm{~L}$. The yearly consumption (WWinhab) would therefore be equal to $7300 \mathrm{~L} \mathrm{inhab}^{-1}$ year $^{-1}$ [15].

- The number of inhabitants in Lebanon was assumed to be equal to $6,000,000$ [16].

- The Dilution Factor was assumed to be equal to 10 as per the EMEA guidelines.

- The fraction of active ingredient excreted unchanged was assumed to be equal to 0.5 when data was not available.

\subsection{Toxicity classification}

Depending on $\mathrm{PEC}_{\mathrm{a}}$ and $\mathrm{PEC}_{\mathrm{b}}$ values obtained for each drug, a different class was assigned to each drug. Drugs were categorized into six classes from the highest to the lowest risk, as explained in table 2.

\section{Results}

\subsection{Anticancer drugs consumption in Lebanon}

The top five drugs with the highest total consumption (2013- 2018) are the following (in decreasing order): Mycophenolate mofetil (MMF), Hydroxycarbamide, Capecitibine, Mycophenolic acid (MPA) and Azathioprine (figure 1).

The most consumed drug, MMF, is an ester prodrug of MPA, classified as a reversible inhibitor of inosine monophosphate dehydrogenase. Once orally administered, MMF is rapidly converted into its active form MPA by hepatic carboxylesterases 1 and $2[18,19]$. Therefore, MMF should be considered as a source of MPA in terms of environmental contamination. Accordingly, consumption data of both drugs were grouped together based on the conversion factor presented in table 1 . The yearly consumption of both drugs and their equivalent total MPA is presented in figure 2 .

The second most commonly consumed drug is Hydroxycarbamide, also known as hydroxyurea. Hydroxycarbamide is an antineoplastic agent that inhibits DNA synthesis through the inhibition of ribonucleoside diphosphate reductase. Once administered, Hydroxyurea is converted to a free radical nitroxide in vivo [20]. The third most commonly consumed drug is capecitabine, an orally-administered chemotherapeutic agent used in the treatment of metastatic breast and colorectal cancers. Capecitabine is a prodrug that is enzymatically converted to fluorouracil (antimetabolite) in the tumor, where it inhibits DNA synthesis and slows growth of tumor tissue $[9,21]$. The environmental toxicity of capecitabine should therefore be analyzed as part of that of Fluorouracil. The yearly consumption of both drugs and their equivalent 5Fluorouracil is presented in figure 3 . The forth most commonly consumed drug is MPA and the fifth is azathioprine, a purine analogue with cytotoxic and immunosuppressive activity. It is prodrug of 6mercaptopurine [22]. Figure 4 illustrates the change in the consumption of each of the commonly consumed chemotherapeutic drugs over the years 2013-2018.

\subsection{Exposure-based classification}

In the first section, the results illustrate the amount of anticancer drugs consumed in Lebanon. In this section, however, in order to better reflect on the exposure to anticancer drugs, several factors are considered (excretion 
and WWTPs removal rates). First, the concentration of each anticancer drug in surface waters was predicted without regard to transformation in the body and removal at WWTPs. This value $\left(P E C_{a}\right)$ is an illustration of the worst case scenario. Then, a new PEC value - $\mathrm{PEC}_{\mathrm{b}}$ - was determined with consideration of the drugs' biotransformation in the body. A third $\mathrm{PEC}$ value, $\mathrm{PEC}_{\mathrm{C}}$, should ideally be calculated to take into consideration the fraction of the drug removed by WWTP. However, due to the absence of efficient WWTP in Lebanon and the absence of data, the $\mathrm{PEC}_{c}$ value calculated would be equal to $\mathrm{PEC}_{\mathrm{b}}$. Details on the $\mathrm{PEC}_{a}$ and $\mathrm{PEC}_{\mathrm{b}}$ results along with the classification of the drugs are presented in a separate document. As we can see in table 3 , most of the drugs belong to class IV and class III, both indicative of a very low risk of environmental toxicity. High risk compounds (class IA) include MMF and MMF equivalent. Potentially hazardous compounds, belonging to class II, include azathioprine, capecitabine, Hydroxycarbamide and MPA, and 5-fluorouracil equivalent. Therefore, from the 259 anti-neoplastic agents available on the Lebanese market, the previously enumerated 6 compounds should be considered as priority for further evaluation. Figure 5 presents the $\mathrm{PEC}_{\mathrm{b}}$ value for the priority anticancer drugs.

\section{Discussion}

\subsection{Analysis of the results}

MMF is the most commonly consumed drug. The main reason behind the elevated consumption of MMF prodrug and its active ingredient MPA is that they are used for as both chemotherapeutic and immunosuppressive agents in organ transplantation as well as auto-immune disease [19]. The analysis of the toxicity of MMF and MPA each separately led to an underestimation of the risks imposed by this drug. Since MMF is a prodrug of MPA, the consumption of both was grouped using drug-specific equivalence factors under a total MPA equivalent (table 1). The PEC values calculated for the MPA equivalent led to risk categorization of the MPA equivalent into either class IIA or class IA for different years, indicating that MPA is a potentially hazardous compound. In contrast, when MPA was analyzed as a separate entity of MMF, it was classified into class IIA and class III for different years, underestimating its potential toxicity. The consumption trend of MMF and MPA was consistent between the years 2013 and 2018. In comparison with global consumption, MMF consumption in Lebanon is $329.22 \mu$ Inhabitant $^{-1}$ Day $^{-1}$, lower than its consumption in Portugal (593 $\mu \mathrm{g}$ Inhabitant ${ }^{-1}$ Day $^{-1}$ ) [17]. As for MPA, its consumption in Lebanon equals $72.03287 \mu$ Inhabitant $^{-1}$ Day $^{-1}$, higher than in Portugal $\left(50 \mu\right.$ Inhabitant $^{-1}$ Day $\left.^{-1}\right)$ ) [17] and Poland $\left(51 \mu\right.$ Inhabitant $^{-1}$ Day $\left.^{-1}\right)$ [23] but lower than in Catalonia (704 $\mu$ Inhabitant $^{-1}$ Day $\left.^{-1}\right)$ [24].

The second most commonly consumed drug is hydroxycarbamide. This could be explained by the fact that hydroxycarbamide is highly consumed in the Middle East and Africa region and it is relatively cheaper than other chemotherapeutic drugs and has several indications [25]. Its consumption approximately doubled between the years 2013 and 2018. It was classified, according to the calculated PEC values, in class IIA (potentially hazardous compounds) for the years 2013-2018. In comparison with global consumption, the consumption of hydroxycarbamide in Lebanon is equal to $140.97 \mu \mathrm{g} \mathrm{Inhabitant}^{-1}$ Day $^{-1}$, higher than in the UK (33 $\mu \mathrm{g} \mathrm{Inhabitant}^{-1}$ Day $\left.^{-1}\right)$ [26] but lower than in Portugal $\left(253 \mu\right.$ Inhabitant $^{-1}$ Day $\left.^{-1}\right)$ [17], Catalonia $(221 \mu \mathrm{g}$ Inhabitant ${ }^{-1}$ Day $\left.^{-1}\right)$ [24] and France (284 $\mu$ Inhabitant $^{-1}$ Day $\left.^{-1}\right)$ [27]. 
The third most commonly consumed drug is Capecitibine. Capecitabine is a widely used chemotherapeutic drug as it has gained approval in two of the most common cancers in Lebanon: breast and colorectal cancer [2]. Additionally, There is a global trend towards the prescribing of capecitabine over fluorouracil as capecitabine allows more patient-friendly oral administration, improved quality of life and fewer side effects [28]. It is worth noting that consumption data of fluorouracil for the years 2014 to 2016 was absent from the provided data. Accordingly, we could not have a clear image on the extent/trend in its consumption. As previously mentioned in the results section, capecitabine is a prodrug of 5-fluorouracil. Accordingly, the consumption of both was grouped using drug-specific equivalence factors under a total 5-fluorouracil equivalent. The PEC values calculated for the equivalent lead to its risk categorization into class IIA for the years 2013-3018, indicating that 5-fluorouracil is a potentially hazardous compound. This again proves that a separate analysis of capecitabine and 5-fluorouracil will lead to an underestimation of the toxicity of each of the drugs, as 5 -fluorouracil analyzed separately was classified into class IV (very low risk). The consumption of capecitabine decreased by one-third between the years 2013 and 2018. In comparison with global consumption, the consumption of capecitabine in Lebanon is equal to $133.09 \mu \mathrm{g} \mathrm{Inhabitant}^{-1}$ Day $^{-1}$, lower than its consumption in Portugal (206 $\mu \mathrm{g} \mu \mathrm{g} \mathrm{Inhabitant}^{-1}$ Day $\left.^{-1}\right)$ [17], Catalonia $\left(280 \mu\right.$ Inhabitant $^{-1}$ Day $\left.^{-1}\right)$ [24], France $\left(213 \mu \mathrm{g} \mathrm{Inhabitant}^{-1}\right.$ Day $\left.^{-1}\right)$ [27] , and UK (183 $\mu$ Inhabitant $^{-1}$ Day $\left.^{-1}\right)$ [26]. As for 5-fluorouracil, its consumption in Lebanon is equal to $6.69 \mathrm{~g} \mathrm{Inhabitant}^{-1} \mathrm{Day}^{-1}$ and it is higher than its consumption in Catalonia $\left(0.70 \mu\right.$ Inhabitant $^{-1}$ Day $\left.^{-1}\right)$ [24] and lower than Portugal $\left(62.50 \mu\right.$ Inhabitant $^{-1}$ Day $\left.^{-1}\right)$ [17], France (71. $\mu$ Inhabitant $^{-1}$ Day $\left.^{-1}\right)$ [27] and UK (46 $\mu$ g Inhabitant $^{-1}$ Day $\left.^{-1}\right)$ [26].

The fifth most commonly consumed drug is Azathioprine. Azathioprine labeled indications are kidney transplantation and rheumatoid arthritis. Its use can be explained by the wide prevalence of rheumatoid arthritis disease in the Lebanese population versus the global population, $1 \%$ and 0.5 to $1 \%$, respectively [29]. Its consumption has remained the same between years 2013 and 2018.Azathioprine was classified, according to the calculated PEC values, in class IIA (potentially hazardous compounds) for the years 2013-2018.

\subsection{Actual Risk}

In this study, we have analyzed the risk imposed by chemotherapeutic micro-pollutants based on their yearly consumption. However, in fact, some chemotherapeutic drugs accumulate and their amounts in the environment build up over the years, alluding to a higher ecotoxicological risk. A review of the environmental fate of the top 5 most consumed drugs reveals that none of them is a potential bio-accumulative drug $[9,28,30]$. However, less commonly consumed chemotherapy drugs that can accumulate and potentially pose a serious environmental risk include: Cyclophosphamide, Ifosfamide [31] and Erlotinib [32].

Another factor that should be taken into consideration is that the residues of pharmaceuticals occur in the environment as complex mixtures, and therefore, even though the concentrations of an individual compound might be low, the cocktail effect might have a more concerning ecotoxicological implication. Research studies on the environmental concern of combinations of anticancer drugs revealed that the interactions of anticancer drugs could be of environmental concern [33-35].

\subsection{Impact on animals/humans}


Studies investigating the toxicity of chemotherapy drugs on animals are scarce and are usually done using higher concentrations than those found in the environment. Accordingly, additional work is needed to evaluate the acute and chronic risks associated with exposure to environmental concentrations. MPA risk evaluation studies revealed that it can cause growth inhibition in green algae. The germination as well as root growth of certain seeds was significantly inhibited by MPA in a concentration-dependent manner. Additionally, the exposure of the cyano-bacterium A. flos-aquae to MPA resulted in a clear concentration-response relationship on the growth rate of the bacteria [36]. A study by Kovacs et al. (2015) evaluated the chronic exposure of zebrafish to 5-Fluorouracil at environmentally relevant concentrations. The results revealed that such exposure causes hepatic and renal histopathological changes, DNA damage and massive whole-transcriptome changes [37]. Another study by Mišík et al. (2016) reports an increased frequency of abortive grains in higher plants exposed to 5-fluorouracil [38].

In addition, with the geographical location of Lebanon in mind, we cannot but highlight the impact of those micropollutants on neighboring countries that share the Mediterranean Sea, including but not limited to Algeria, Croatia, Cyprus, Egypt, France and Greece.

\subsection{The need for regulations}

\subsubsection{The importance of WWTPS}

Pharmaceutical compounds are designed to have desirable target effects in the human body, but the impact of chronic indirect exposure to these compounds can be dangerous for both humans as well as other species. Anticancer drugs have potent cytotoxic, genotoxic, mutagenic, carcinogenic, endocrine disruptor as well as teratogenic effects. The augmentation of cancer disease in the Lebanese population has led to an increase in the drug consumption and therefore an increase in drug discharge into the environment. Therefore, it is indeed essential to pay special attention to the discharge of anticancer drugs in the environment and the development of effective WWTPs. It is worth noting that not all waste water treatment techniques are effective at removing anticancer drugs. The scarce literature available shows that a promising method for the removal of micropollutants is the membrane bioreactor (MBR), which combines physical removal with biological removal (biodegradation) to improve the outcome of the water treatment [6].

\subsubsection{Pharmaceutical waste management in Lebanon}

In this paper, we have tackled the risks imposed by a major source of chemotherapeutic drug in surface waters: the chemotherapeutic drugs consumed by the patients in medical centers as well as their home. However, another major source of micropolluants are expired/unused drugs that stay at the importer's warehouses and do not reach hospitals/patients. In the absence of a safe solution and the necessary regulations to dispose of pharmaceutical surplus, warehouses in Lebanon are filling up with old, expired drugs [39].

\subsubsection{Need for regulations}

Efforts are needed to set new policies regarding the disposal of micropollutants in general, and chemotherapeutic drugs primarily. We hope that this research study sheds light on the risk imposed by chemotherapeutic drugs and contributes to future establishment and enforcement of regulations to protect the public from the danger of such micropullutants in surface waters. 


\subsection{Future studies needed}

Our research study is the first of its kind in Lebanon and the Middle East. As previously stated, in this study, we have estimated the environmental concentrations in surface waters by the calculation of PECs based on consumption data. Reports on the occurrence of chemotherapeutic drugs in surface water, ground water or drinking water by measurement of actual of the drug concentrations are absent.

\section{Conclusions}

This work presents, for the first time, an extensive analysis of the consumption rates of 259 different anticancer drugs dispensed in Lebanon between 2013 and 2018. Globally, there is a growing attention regarding the fate of pharmaceuticals in the environment and their potential toxicity to different species. All pharmaceuticals, by design, are meant to elicit a biological response. Chemotherapeutic drugs are of a particular concern, as these drugs were designed to damage DNA, inhibit DNA synthesis, and interrupt cell replication. They act unselectively on all growing cells and have mutagenic potency. The analysis showed that the top five most commonly consumed drugs are: MMF, hydroxycarbamide, capecitabine, MPA and azathioprine. A preliminary analysis of the toxicity risk based on the assessment of exposure allowed the identification of six potentially priority drugs, belonging to classes IA (high risk compounds) and IIA (potentially hazardous compounds): MMF, hydroxycarbamide, capecitabine, MPA, azathioprine and 5-fluorouracil. Our analysis has also proven that, when analyzing the potential risk of such micropollutants, it is a key pre-requisite to combine drugs with common end product, as their toxicity cannot be separated. Further analysis of these priority micropollutants is necessary, with actual measurement, rather than estimation, of their occurrence in surface waters. In this study, we have shed light on potential contaminants of our surface waters, emphasizing the importance of efficacious WWTPs and the enforcement of regulations with regard to environmental pollution.

\section{Declarations}

\section{Acknowledgements:}

The authors thank the Lebanese American University for financing this research project.

\section{Availability of data and materials:}

All data generated or analyzed during this study are included within the article except for the raw data provided by the MOPH, which will be provided upon request.

\section{Authors' contributions:}

Y. Saab was responsible for the conceptualization and design of the study, acquisition of the data and critical data analysis and revision of the manuscript. Z. Nakad developed the software needed for the calculations and processed the data. R. Rahme worked on the computation and interpretation of data and drafted the article. All authors read and approved the final manuscript.

\section{Competing interests:}


The authors declare they have no competing interests.

\section{Funding:}

This research paper was funded by the Lebanese American University.

\section{Author's Information:}

Z. Nakad, received his B.E. degree in Computer and Communication Engineering with distinction from the American University of Beirut in 1998. He later received his M.S. and Ph.D. in Computer Engineering from Virginia Tech in 2000 and 2003 respectively. Zahi Nakad joined the Lebanese American University in 2004 and is currently an Associate Professor in Computer Engineering.

znakad@lau.edu.lb

R. Rahme, B.S. in pharmacy, M.S. in Pharmaceutical Development and Management candidate, Lebanese American University.

Rita.rahme@lau.edu

Y. Saab, B.S. Pharm, Pharm.D, PhD

Associate Professor, School of Pharmacy, Lebanese American University, Byblos, Lebanon, P.O.Box: 36, F-19

ysaab@lau.edu.lb

TEL \#: 961-9-547 254/262, Ext. 2312

FAX \#: 961-9-547 256

\section{References}

1. 2020. In: Who.int. https://www.who.int/news-room/fact-sheets/detail/cancer. Accessed 15 Dec 2020

2. Cancer Country Profile 2020- Burden of Cancer- Lebanon. In: Who.int. https://www.who.int/cancer/countryprofiles/LBN_2020.pdf. Accessed 20 Oct 2020

3. Anticancer Drug Classes. In: Pharmacology2000.com. https://www.pharmacology2000.com/Chemotherapy/Anticancer/classes1.htm. Accessed 21 Oct 2020.

4. BALCERZAK W, REZKA P. Occurrence of anti-cancer drugs in the aquatic environment and efficiency of their removal - the selected issues. Technical transactions- environment engineering.2014. Accessed 21 Oct 2020.

5. Jureczko M, Kalka J. Cytostatic pharmaceuticals as water contaminants. Eur J Pharmacol. 2020. 866:172816.

6. Climent LF. Analysis of chemotherapy drugs and related compounds in aquatic environment: removal, transformation and risk evaluation in eco-friendly and advanced technologies. 2016. www.tdx.cat s bitstream > handle > tlfc_20161128. Accessed 21 Oct 2020. 
7. Tambosi JL, Yamanaka LY, José HJ, Moreira R de FPM, Schröder HF. Recent research data on the removal of pharmaceuticals from sewage treatment plants (STP). Quím Nova. 2010;33(2):411-20.

8. Mycophenolate mofetil - Drug Summary. In: Pdr.net. https://www.pdr.net/drug-summary/cellcept? druglabelid=988. Accessed 5 Nov 2020.

9. Straub J. Combined Environmental Risk Assessment for 5-Fluorouracil and Capecitabine in Europe. Integrated Environmental Assessment and Management https://setac.onlinelibrary.wiley.com/doi/abs/10.1897/IEAM_2009-073.1. Accessed 20 May 2020.

10. Green DM, Nolan VG, Goodman PJ, Whitton JA, Srivastava D, Leisenring WM, et al. The Cyclophosphamide Equivalent Dose as an Approach for Quantifying Alkylating Agent Exposure. A Report from the Childhood Cancer Survivor Study. Pediatr Blood Cancer. 2014. Accessed 5 Nov 2020.

11. Shankar SM, Marina N, Hudson MM, Hodgson DC, Adams MJ, Landier W, et al. Monitoring for cardiovascular disease in survivors of childhood cancer: report from the Cardiovascular Disease Task Force of the Children's Oncology Group. Pediatrics. 2008. Accessed 18 Nov 2020.

12. Izbicka E, Diaz A, Streeper R, Wick M, Campos D, Steffen R, et al. Distinct mechanistic activity profile of pralatrexate in comparison to other antifolates in in vitro and in vivo models of human cancers. Cancer Chemother Pharmacol. 2009. doi: 10.1007/s00280-009-0954-4. Accessed 18 Nov 2020.

13. Fujii Y, Yonese J, Kawakami S, Yamamoto S, Okubo Y, Fukui I. Equivalent and sufficient effects of leuprolide acetate and goserelin acetate to suppress serum testosterone levels in patients with prostate cancer. BJU Int. 2008. 10.1111/j.1464-410X.2007.07374.x Accessed 18 Dec 2020.

14. Environmental Assessment of Human Drug and Biologics Applications. U.S. Food and Drug Administration. 1998. https://www.fda.gov/regulatory-information/search-fda-guidancedocuments/environmental-assessment-human-drug-and-biologics-applications. Accessed 15 Jan 2020.

15. Environmental risk assessment of medicinal products for human use - European Medicines Agency. European Medicines Agency. 2006. https://www.ema.europa.eu/en/environmental-risk-assessmentmedicinal-products-human-use. Accessed 15 Jan 2020.

16. Lebanon Population (2020) - Worldometer. https://www.worldometers.info/world-population/lebanonpopulation/ Accessed 02 January 2021.

17. Santos MSF, Franquet-Griell H, Lacorte S, Madeira LM, Alves A. Anticancer drugs in Portuguese surface waters - Estimation of concentrations and identification of potentially priority drugs. Chemosphere. 2017. 10.1016/j.chemosphere.2017.06.102. Accessed 02 January 2021.

18. Mycophenolate mofetil. PubChem. https://pubchem.ncbi.nlm.nih.gov/compound/5281078. Accessed 02 January 2021.

19. Mycophenolate mofetil. DrugBank Online. 2021. https://www.drugbank.ca/drugs/DB00688. Accessed 02 January 2021.

20. Pubchem.ncbi.nlm.nih.gov.2021. https://pubchem.ncbi.nlm.nih.gov/compound/3657. Accessed 20 December 2019.

21. Pubchem.ncbi.nlm.nih.gov.2021 https://pubchem.ncbi.nlm.nih.gov/compound/60953 Accessed 20 December 2019.

22. Pubchem.ncbi.nlm.nih.gov. 2021 https://pubchem.ncbi.nlm.nih.gov/compound/2265. Accessed 20 December 2019. 
23. Giebułtowicz J, Nałęcz-Jawecki G. Occurrence of immunosuppressive drugs and their metabolites in the sewage-impacted Vistula and Utrata Rivers and in tap water from the Warsaw region (Poland). Chemosphere. 2016. DOI: 10.1016/j.chemosphere.2015.12.135. Accessed 14 January 2020..

24. Predicting concentrations of cytostatic drugs in sewage effluents and surface waters of Catalonia (NE Spain) | Elsevier Enhanced Reader. 2015 https://doi.org/10.1016/j.envres.2015.02.015. Accessed 14 January 2020.

25. Global Hydroxycarbamide Market 2021-2025 Covid 19 Impact on Top Countries Data -Key Leaders Analysis, Segmentation, Growth, Future Trends, Gross Margin, Demands, Emerging Technology by Regional Forecast. MarketWatch. 2021 https://www.marketwatch.com/press-release/global-hydroxycarbamidemarket-2021-2025-covid-19-impact-on-top-countries-data-key-leaders-analysis-segmentation-growthfuture-trends-gross-margin-demands-emerging-technology-by-regional-forecast-2020-12-16. Accessed 14 January 2020.

26. Johnson AC, Jürgens MD, Williams RJ, Kümmerer K, Kortenkamp A, Sumpter JP. Do cytotoxic chemotherapy drugs discharged into rivers pose a risk to the environment and human health? An overview and UK case study. J Hydrol. 2008. https://doi.org/10.1016/j.jhydrol.2007.09.054

27. Besse J-P, Garric J. Human pharmaceuticals in surface waters: Implementation of a prioritization methodology and application to the French situation. Toxicol Lett. 2008. DOI: 10.1016/j.toxlet.2007.10.012

28. Kosjek T, Perko S, Žigon D, Heath E. Fluorouracil in the environment: Analysis, occurrence, degradation and transformation. J Chromatogr A. 2013. https://doi.org/10.1016/j.chroma.2013.03.046.

29. CHAAYA M, SLIM Z, HABIB R, ARAYSSI T, DANA R, HAMDAN 0 et al. High burden of rheumatic diseases in Lebanon: a COPCORD study. International Journal of Rheumatic Diseases. 2011. 10.1111/j.1756185X.2011.01682.x Accessed 04 March 2020.

30. Mišík M, Filipic M, Nersesyan A, Kundi M, Isidori M, Knasmueller S. Environmental risk assessment of widely used anticancer drugs (5-fluorouracil, cisplatin, etoposide, imatinib mesylate). Water Research. 2019. https://pubmed.ncbi.nlm.nih.gov/31404901/. Accessed 04 March 2020.

31. Kümmerer K, Al-Ahmad A. Estimation of the cancer risk to humans resulting from the presence of cyclophosphamide and ifosfamide in surface water. Environ Sci Pollut Res. 2010. 10.1007/s11356-0090195-4. Accessed 17 Avril 2020.

32. Environmental Risk Assessment Summary- Erlotinib. Roche.com. 2020. https://www.roche.com/dam/jcr:5705fc1e-a9fa-4389-aa9c-443bcbd2493d/en/erlotinib-ERA-summary2020.pdf

33. Kundi M, Parrella A, Lavorgna M, Criscuolo E, Russo C, Isidori M. Prediction and assessment of ecogenotoxicity of antineoplastic drugs in binary mixtures. Environ Sci Pollut Res. 2016. DOI: 10.1007/s11356-015-4884-x. Accessed 10 May 2020.

34. Heath, E., Filipič, M., Kosjek, T. et al. Fate and effects of the residues of anticancer drugs in the environment. Environ Sci Pollut. 2016. https://doi.org/10.1007/s11356-016-7069-3. Accessed 10 May 2020.

35. Mišík M, Filipic M, Nersesyan A, Mišíková K, Knasmueller S, Kundi M. Analyses of combined effects of cytostatic drugs on micronucleus formation in the Tradescantia. Environ Sci Pollut Res. 2016. 10.1007/s11356-015-5837-0. Accessed 10 July 2020. 
36. Straub JO, Oldenkamp R, Pfister T, Häner A. Environmental Risk Assessment for the Active Pharmaceutical Ingredient Mycophenolic Acid in European Surface Waters. Environ Toxicol Chem. 2019. https://doi.org/10.1002/etc.4524. Accessed 07 July 2020.

37. Kovács R, Csenki Z, Bakos K, Urbányi B, Horváth Á, Garaj-Vrhovac V, et al. Assessment of toxicity and genotoxicity of low doses of 5-fluorouracil in zebrafish (Danio rerio) two-generation study. 2015. Doi:10.1007/s801090000086. Accessed 07 July 2020.

38. Mišík M, Kundi M, Pichler C, Filipic M, Rainer B, Mišíková K et al. Impact of common cytostatic drugs on pollen fertility in higher plants. Environmental Science and Pollution Research. 2015. https://pubmed.ncbi.nlm.nih.gov/25779110/ Accessed 15 June 2020.

39. Expired pharmaceuticals dumped in warehouses. The Daily Star Newspaper - Lebanon. 2017. https://www.dailystar.com.lb/News/Lebanon-News/2017/Apr-27/403519-expired-pharmaceuticalsdumped-in-warehouses.ashx Accessed 21 July 2020.

\section{Tables}

Table 1 Active ingredients in each class of anticancer drugs and the factors used in the conversion. 


\section{Drug class}

Inosine monophosphate

dehydrogenase inhibitor

1. Mycophenolic acid

Active ingredients Conversion factor (MPA)

2. Mycophenolate

mofetil (MMF)

1. Capecitabine

$1440 \mathrm{mg}$ MPA = $2000 \mathrm{mg}$ MMF [8]

Antimetabolites
2. 5-Fluorouracil

2.76 mg CAP = $1 \mathrm{mg}$ 5-Fluorouracil [9]

Alkylating agents

1. Cyclophosphamide

$1 \mathrm{mg}$ cyclophosphamide $=0.244$ ifosfamide [10]

2. Ifosfamide

Anthracyclins

1. Epirubicin $\mathrm{HCl}$

$75 \mathrm{mg}$ Epirubicin $=12.5 \mathrm{mg}$ Mitoxantrone $=50$ mg Doxorubicin $=10 \mathrm{mg}$ idarubicin [11]

2. Mitoxantrone

3. Doxorubicin

4. Idarubicin $\mathrm{HCl}$

Taxanes

1. Docetaxel 135 mg Paclitaxel = 75 mg Docetaxel

2. Paclitaxel

Antimetabolites

1. Methotrexate $1.5 \mathrm{mg}$ Methotrexate = $150 \mathrm{mg}$ Pemetrexed [12]

2. Pemetrexed

LHRH agonist: Goserelin equivalent
1. Goserelin

2. Leuprorelin

3. Triptorelin
$3.6 \mathrm{mg}$ Goserelin= $7.5 \mathrm{mg}$ Leuprorelin $=3.75$ mg Triptorelin [13] 
Table 2 Classification of compounds based on potential exposure $\left(\mathrm{PEC}_{\mathrm{a}}\right.$ and $\mathrm{PEC}_{\mathrm{b}}$ values): risk categories.

\begin{tabular}{lc}
\hline \multicolumn{1}{c}{ Class } & Risk \\
\hline Class IA & High risk compounds \\
Class IB & Potentially hazardous compounds but limited data \\
\hline Class IIA & Potentially hazardous compounds \\
\hline Class IIB & Unclassified risk \\
\hline Class III & Very low risk \\
\hline Class IV & Very low risk \\
\hline
\end{tabular}

Table 3 Risk categorization of chemotherapeutic drugs based on environmental exposure data between 2013 and 2018. 


\begin{tabular}{|c|c|c|c|c|c|}
\hline \multirow{2}{*}{$\frac{\text { ASS IA }}{\text { ihenolate }}$} & \multirow{2}{*}{$\begin{array}{c}\text { Class IIA } \\
\text { Azathioprine }\end{array}$} & \multirow{2}{*}{$\begin{array}{c}\text { Class III } \\
\text { Mycophenolic }\end{array}$} & \multicolumn{3}{|c|}{ CLASS IV } \\
\hline & & & Imatinib (2017- & Epirubicin $\mathrm{HCl}$ & Pomalidomide \\
\hline il (2013- & (2013-2015,2017- & acid (2013) & 2018) & Eribulin & Pralatrexate \\
\hline 1,2016$)$ & 2018) & Tamoxifen & Afatinib & mesylate & Regorafenib \\
\hline phenolic & Capecitibine & $(2015-2018)$ & Imatinib & Erlotinib & Ribociclib \\
\hline rcid & Hydroxycarbamide & Imatinib & Alectinib & Etoposide & Ruxolitinib \\
\hline ivalent & Mycophenolate & $(2013-2016)$ & Anastrazole & Everolimus & Sirolimus \\
\hline \multirow[t]{24}{*}{ 016) } & mofetil (2015, & Azathioprine & Apremilast & Exemestane & Sorafenib \\
\hline & $2017,2018)$ & (2016) & Axitinib & Fingolimod & Sunitinib \\
\hline & Mycophenolic acid & Ciclosporin & Azacitidine & Fludarabine & maleate \\
\hline & $(2014-2018)$ & $(2014)$ & Baricitinib & Fluorouracil & Tacrolimus \\
\hline & Mycophenolic acid & & Bendamustine $\mathrm{HCl}$ & Fulvestrant & monohydrate \\
\hline & equivalent (2013- & & Bicalutamide & Gefitinib & Temozolomide \\
\hline & $2015,2017-2018)$ & & Bleomycin & Goserelin & Teriflunomide \\
\hline & 5-fluorouracil & & Busulfan & Ibrutinib & Thalidomide \\
\hline & equivalent & & Cabazitaxel & Idarubicin $\mathrm{HCl}$ & Tofacitinib \\
\hline & & & Carboplatin & Ifosfamide & Trabectedin \\
\hline & & & Carfilzomib & Irinotecan $\mathrm{HCl}$ & Trifluridine \\
\hline & & & Ciclosporin & Lapatinib & Triptorelin \\
\hline & & & $(2013,2015-2018)$ & ditosylat & Vemurafenib \\
\hline & & & Cisplatin & Leflunomide & Venetoclax \\
\hline & & & Clofarabine & Lenalidomide & Vincristine \\
\hline & & & Cladribine & Lenvatinib & sulfate \\
\hline & & & Crizotinib & Letrozole & Vinflumine \\
\hline & & & Cyclophosphamide & Leuprorelin & Vinorelbine \\
\hline & & & Cytarabine & Mercaptopurine & Vismodegib \\
\hline & & & Dacarbazine & Mitoxantrone & Oxaliplatin \\
\hline & & & Dasatinib & Nilotinib & Gemcitabine \\
\hline & & & Decitabine & Nintedanib & Methotrexate \\
\hline & & & Degarelix & Osimertinib & Tamoxifen \\
\hline & & & Docetaxel & Paclitaxel & $(2013-2014)$ \\
\hline
\end{tabular}




$\begin{array}{ccc}\text { Doxorubicin } & \text { Palbociclib } & \text { Methotrexate } \\ \text { Enzalutamide } & \text { Pazopanib HCl } & \text { equivalent } \\ \text { Pemetrexed } & \text { Docetaxel } \\ \text { Plerixafor } & \text { equivalent } \\ \text { Methotrexate } & \text { Doxorubicin } \\ \text { equivalent } & \text { equivalent } \\ & \text { Goserelin } \\ & \text { equivalent }\end{array}$

Table 4 PECa, PECb and risk categorization of the priority anticancer drug and their corresponding equivalents between the years 2013 and 2018. 


\begin{tabular}{|c|c|c|c|c|c|c|c|}
\hline Active Ingredient & factor & 2013 & 2014 & 2015 & 2016 & 2017 & 2018 \\
\hline \multirow[t]{3}{*}{ Azathioprine } & PECa & 46.94 & 29.61 & 27.37 & 13.08 & 26.97 & 51.14 \\
\hline & $\mathrm{PECb}$ & 23.47 & 14.8 & 13.68 & 6.54 & 13.48 & 25.57 \\
\hline & Class & IIA & IIA & IIA & III & IIA & IIA \\
\hline \multirow[t]{3}{*}{ Capecitibine } & $\mathrm{PECa}$ & 98.98 & 74.17 & 83.78 & 83.17 & 83.17 & 54.38 \\
\hline & $\mathrm{PECb}$ & 49.49 & 37.08 & 41.89 & 41.58 & 41.58 & 27.19 \\
\hline & Class & IIA & IIA & IIA & IIA & IIA & IIA \\
\hline \multirow[t]{3}{*}{ 5- fluorocuracil } & PECa & 1.49 & NA & NA & NA & 1.92 & 7.95 \\
\hline & $\mathrm{PECb}$ & 0.74 & NA & NA & NA & 0.96 & 3.97 \\
\hline & Class & IV & NA & NA & NA & IV & IV \\
\hline \multirow[t]{3}{*}{ Mycophenolic acid } & PECa & 12.19 & 41.31 & 62.09 & 56.65 & 38.43 & 43.41 \\
\hline & $\mathrm{PECb}$ & 6.10 & 20.66 & 31.05 & 28.33 & 19.21 & 21.70 \\
\hline & Class & III & IIA & IIA & IIA & IIA & IIA \\
\hline \multirow[t]{3}{*}{ Mycophenolate mofetil } & PECa & 218.05 & 212.46 & 167.76 & 233.49 & 161.20 & 185.93 \\
\hline & $\mathrm{PECb}$ & 109.03 & 106.23 & 83.88 & 116.74 & 80.60 & 92.97 \\
\hline & Class & IA & IA & IIA & IA & IIA & IIA \\
\hline \multirow[t]{3}{*}{ Hydroxycarbamide } & PECa & 64.77 & 117.93 & 73.10 & 54.83 & 77.10 & 115.25 \\
\hline & $\mathrm{PECb}$ & 32.38 & 58.96 & 36.55 & 27.41 & 38.55 & 57.62 \\
\hline & Class & IIA & IIA & IIA & IIA & IIA & IIA \\
\hline \multirow[t]{3}{*}{ Mycophenolic acid equivalent } & PECa & 169.19 & 194.28 & 182.88 & 224.76 & 154.49 & 177.28 \\
\hline & $\mathrm{PECb}$ & 84.59 & 97.14 & 91.44 & 112.38 & 77.25 & 88.64 \\
\hline & Class & IIA & IIA & IIA & IA & IIA & IIA \\
\hline 5-fluorouracil equivalent & PECa & 37.35 & 26.87 & 30.36 & 30.14 & 32.06 & 27.65 \\
\hline
\end{tabular}




$\begin{array}{ccccccc}\mathrm{PECb} & 18.67 & 13.44 & 15.18 & 15.07 & 16.03 & 13.83 \\ \text { Class } & \text { IIA } & \text { IIA } & \text { IIA } & \text { IIA } & \text { IIA } & \text { IIA }\end{array}$

Figures

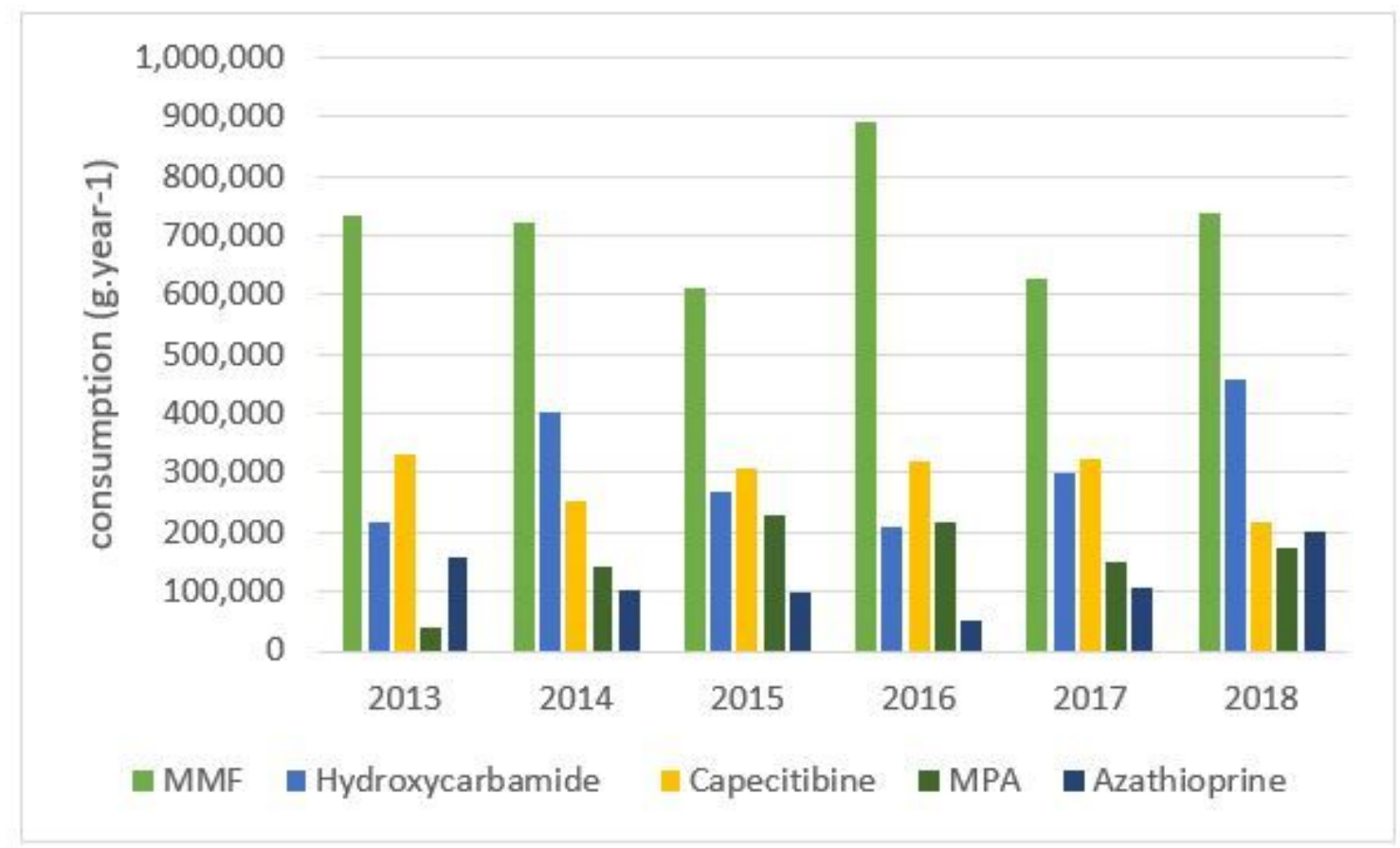

Figure 1

Top 5 most commonly consumed anticancer drugs in Lebanon between 2013 and 2018. 


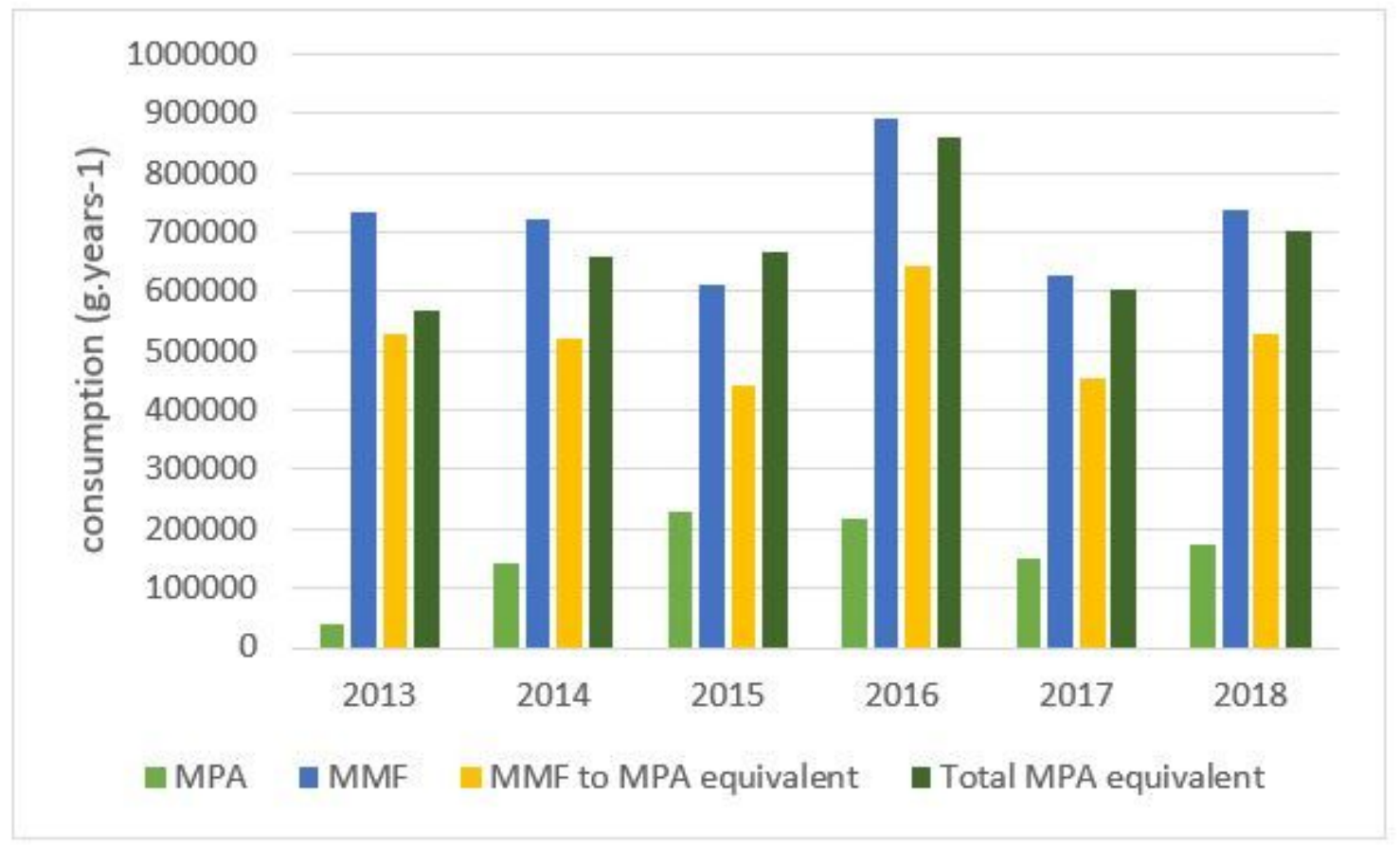

Figure 2

Yearly consumption of MMF, MPA and their equivalent MPA between 2013 and 2018.

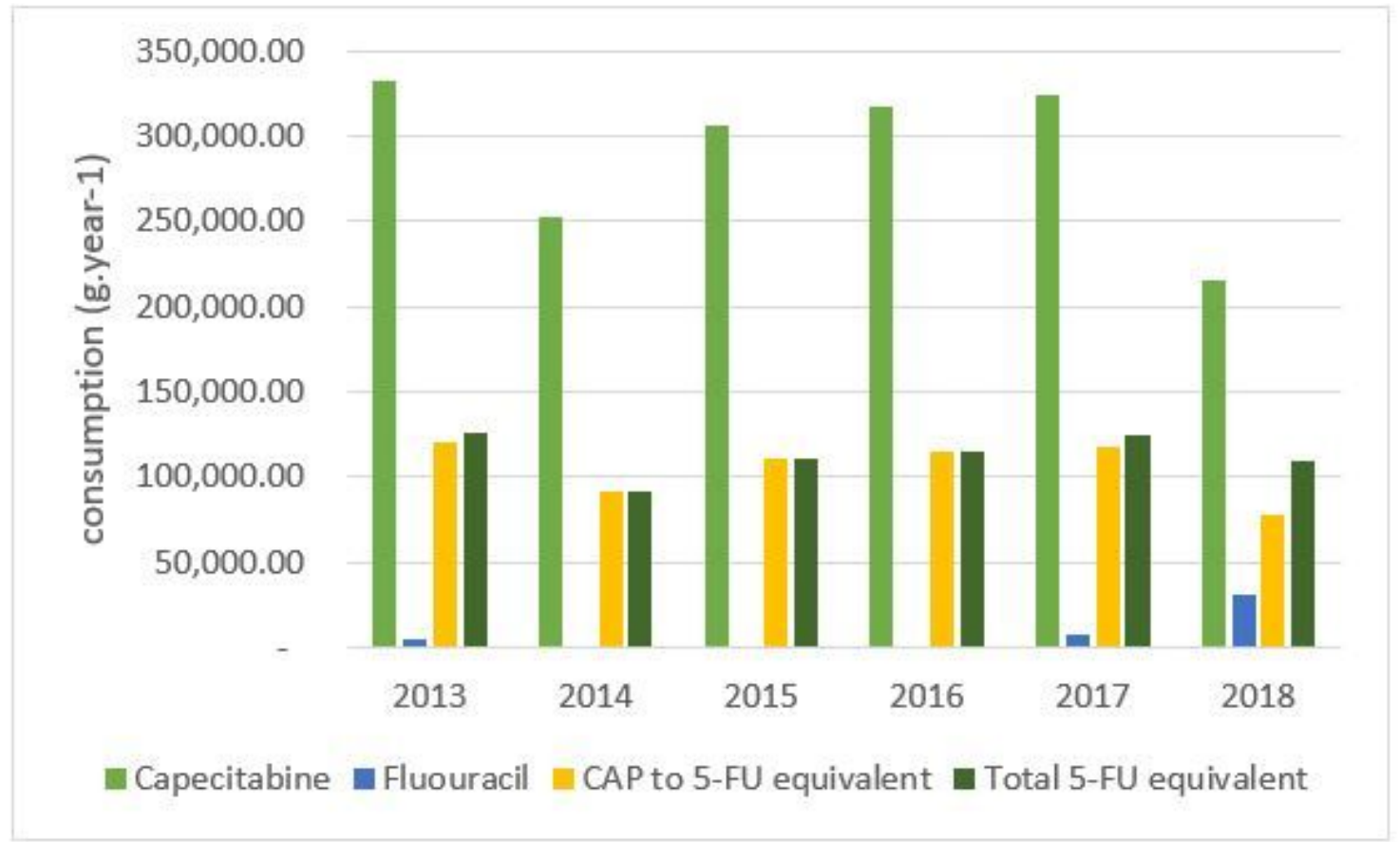

Figure 3

Yearly consumption of capecitabine, 5-fluorouracil, and their equivalent (2013-2018). 


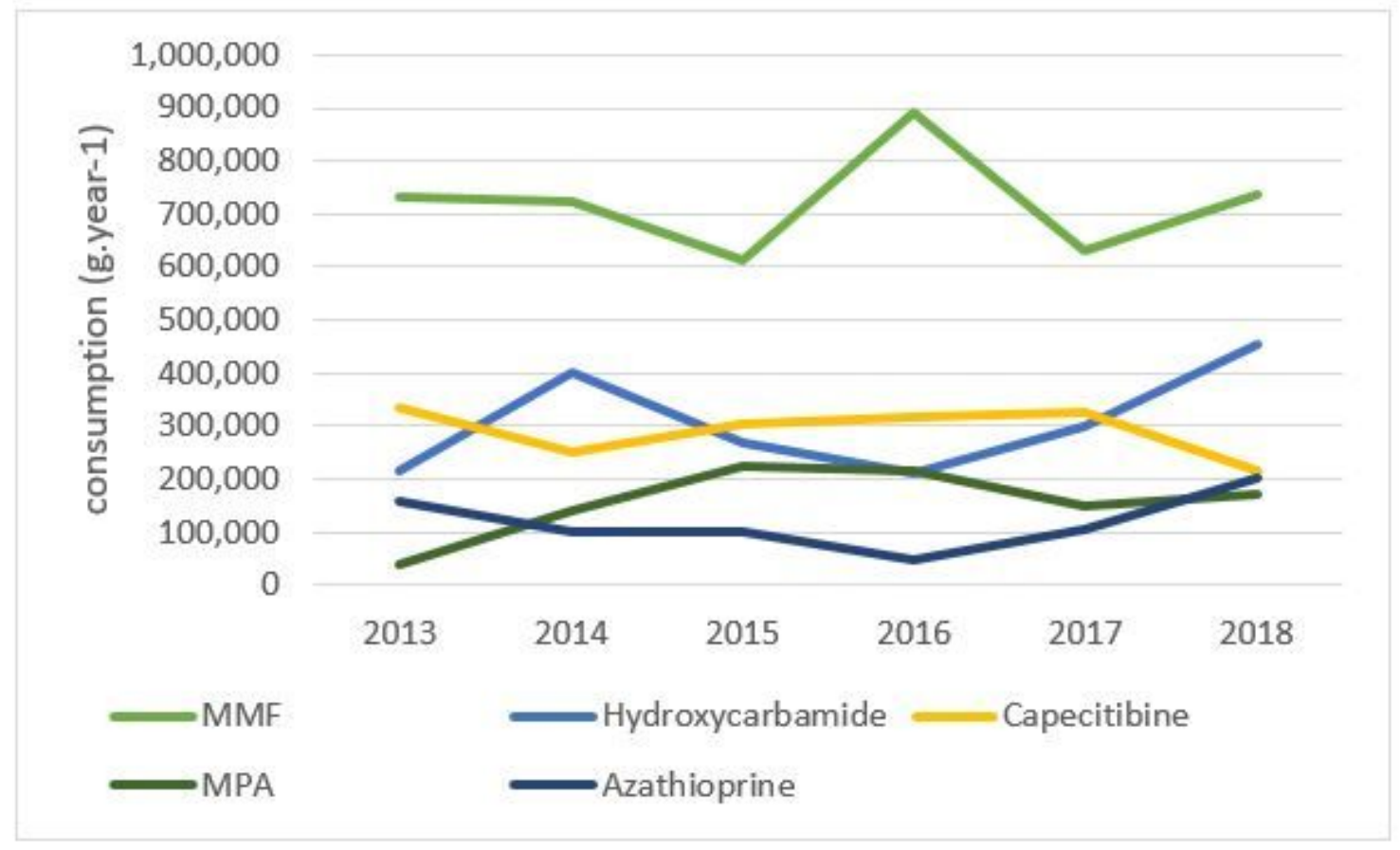

Figure 4

Trend in the consumption of commonly prescribed chemotherapeutic drugs (2013-2018).

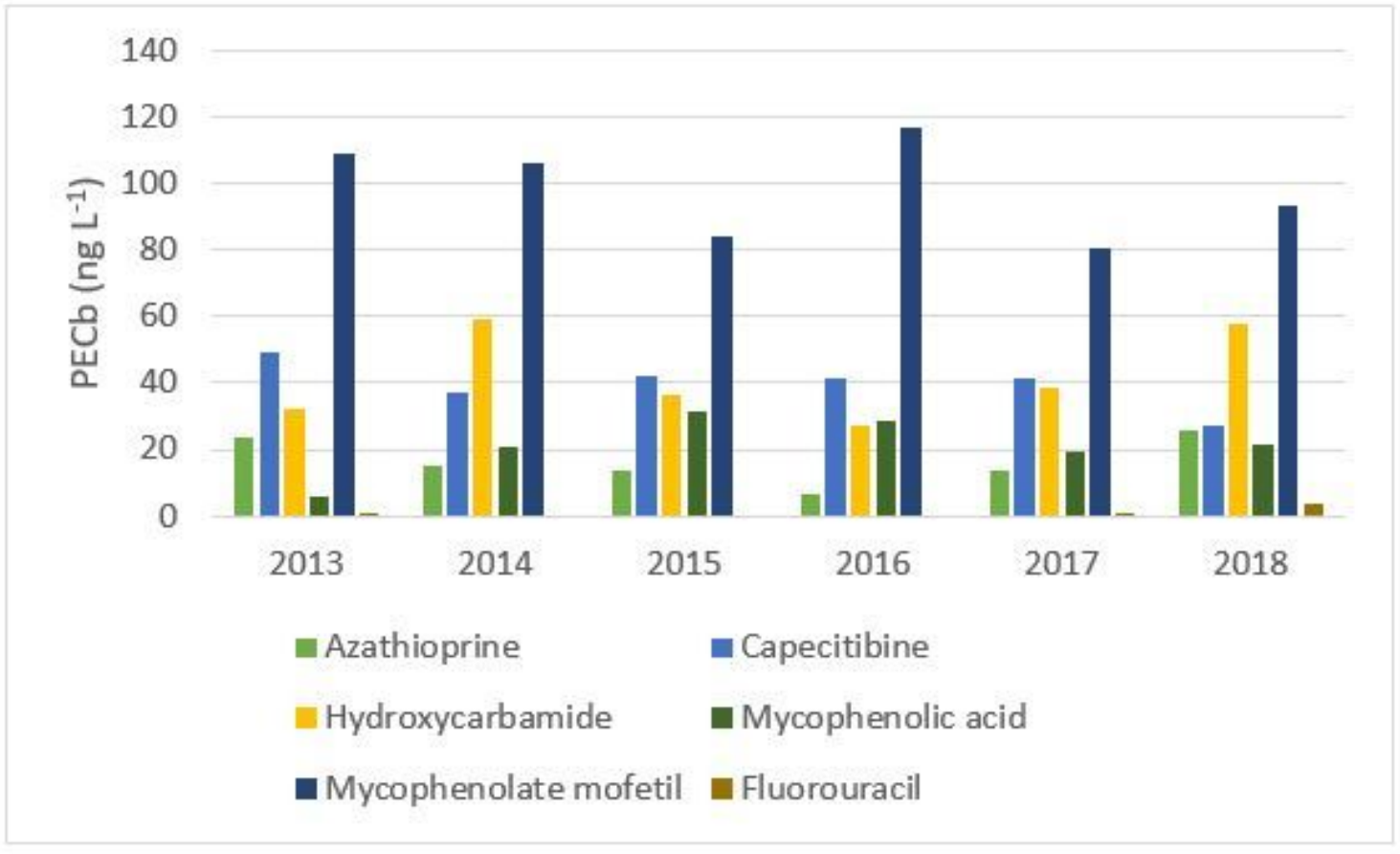

Figure 5

PEC $b$ value of the 6 priority chemotherapeutic drugs in Lebanon.

\section{Supplementary Files}


This is a list of supplementary files associated with this preprint. Click to download.

- Scheme1.jpg 